\title{
Multi-Objective Scheduling Using Genetic Algorithms
}

\author{
M. S. Al-Ashhab ${ }^{* 1,2}$ and E. A. Mlybari ${ }^{3}$ \\ ${ }^{1}$ Design \& Production Engineering Dept. Faculty of Engineering, \\ Ain-Shams University-Egypt \\ ${ }^{2}$ Dept. of Mechanical Engineering, College of Engineering and Islamic architecture, \\ Umm Al-Qura University, Makkah, Saudi Arabia. \\ ${ }^{3}$ Dept. of Civil Engineering, College of Engineering and Islamic architecture, \\ Umm Al-Qura University, Makkah, Saudi Arabia. \\ *Corresponding author email: msashhab@uqu.edu.sa
}

\begin{abstract}
In this article, a multi-objective scheduling optimization model using Genetic Algorithms is proposed to minimize makespan (maximum completion time), total tardiness and total earliness simultaneously. Many other objectives like maximum tardiness, maximum earliness, and a minimum number of tardy jobs can be optimized easily using the proposed model. The model has been carried out using the MS Excel spreadsheets and an add-in to provide the GA which is known as Evolver. A set of projects has been used to examine the model and its effectiveness has been proven. The proposed model is more flexible than other existing software with superior performance and accurate results comparing with what is obtained for others like LEKIN.
\end{abstract}

Keywords: JSSP; Genetic Algorithm; Multi-Objective Optimization; Evolver.

\section{Introduction}

Best allocating the suitable equipment to perform the required jobs over time to achieve the business goals is the mission of the scheduling process. Therefore, many efforts have been devoted to solving optimally Job Shop Scheduling Problems (JSSP). Minimizing the maximum completion time was the common objective of the majority of these researches. JSSP is an NP-hard problem; so, it is difficult to find an exact solution in a reasonable computation time [1]. A variety of optimization methods have been developed to solve JSSP, Tabu Search [2, 3], Simulated Annealing [4, 5], Genetic Algorithms [6, 7], Particle Swarm Optimization [8, 9], Ant Colony Optimization [10, 11], differential evolution algorithm [12], Memetic Algorithm [13], Mathematical Programming [14, 15], and Goal Programming [16].

Most researches tackled the scheduling problems as a single objective optimization problem [6,7,15,17,18]. The scheduling process requires a multi-objective treatment to consider conflicting objective [19]. So, researchers often deal with problems that involve multiple usually conflicting criteria [20].

There are many approaches to optimize multi-objectives. Individual objective functions can be combined into a single composite function and in this combination, the single objective is possible to be determined with methods such as weighted sum method. Moving objectives to be constraints can be done as the constraining values must be established for each of these former objectives. In lexicographic procedures, objectives are prioritized and ordered according to the prioritization results [21].

A variety of evolutionary algorithms have been successfully extended to solve MOP, such as SPEA2 [22] and NSGA-II [23], which are based on Pareto dominance, Genetic Algorithms (GA) [24-27], Ant Colony System (ACS) [28-31], Particle Swarm Optimization (PSO) [32-36], A Non-Dominated Neighbor Immune Algorithm [37] and Estimation of Distribution Algorithm (EDA) [38-41].

Genetic Algorithm has the advantage to solve scheduling problems. It has the ability to find to reach optimal or sub-optimal solutions. It has gained the advantage of searching for the global optimization solution in a huge population.

The Microsoft Excel spreadsheet and an add-in to provide the GA called Evolver are used by I. Chaudhry, I. A. Chaudhry et al., Chaudhry et al., and. Al-Ashhab and H. Fadag [42-45] in the domain of scheduling problems. The use of this software demonstrates how simple it is to implement the genetic algorithm to optimize the scheduling problems. The author decided to get benefit from this advantage of using Evolver. This research uses a spreadsheet-based commercial genetic algorithm Evolver to solve a multi-objective scheduling model using GA. 
The aim of this paper is to present a multi-objective job shop scheduling model using Genetic Algorithms to minimize maximum completion time, total tardiness and total earliness criteria using the spreadsheet-based GA approach.

\section{Problem Description and Assumptions}

Solving a multi-objective scheduling problem is the goal of this model. The spreadsheet-based commercial genetic algorithm solver "Evolver" [46] is used to optimize the multi-objective functions mentioned in Equation 4. Figure 1 describes the Microsoft Excel-Evolver integration architecture [47].

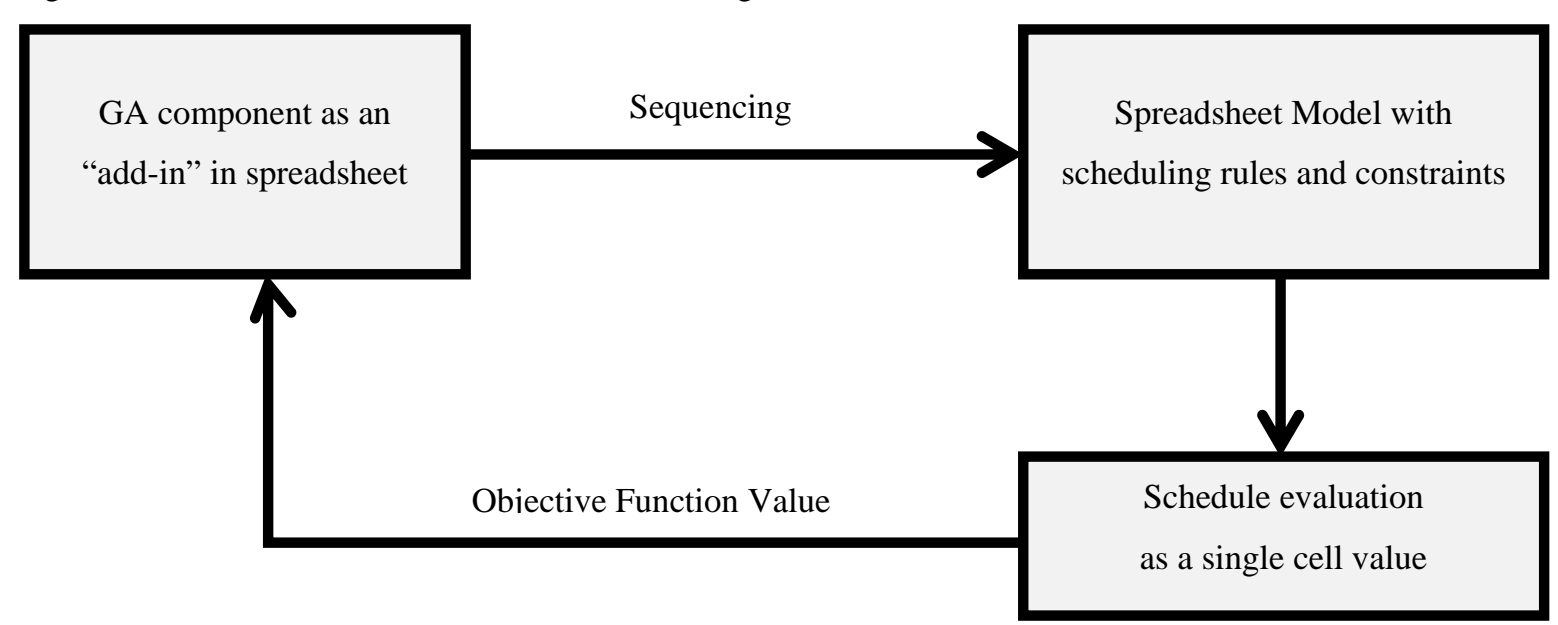

Figure 1. Microsoft Excel-Evolver integration architecture.

Classical Job Shop Scheduling Problems (JSSP) considers the allocation of $\mathrm{n}$ jobs to $\mathrm{m}$ different machines or equipment. Each job has to undergo multiple operations on various equipment and each job has its own set of processing times and routing characteristics. The processing time of each job on each equipment Phj is known and the due date for each job as well $\mathrm{Dj}$.

\section{The following assumptions are considered in the model:}

$\checkmark \quad$ Each job has its own due date;

$\checkmark$ Each job does not visit the same equipment twice;

$\checkmark \quad$ All jobs are ready for processing at time zero;

$\checkmark \quad$ All equipment are available at time zero;

$\checkmark$ Each equipment can process only one job at a time;

$\checkmark \quad$ Only one job can be processed by an equipment at any instant in time;

$\checkmark$ The processing times are known, fixed, and independent of the sequence;

$\checkmark$ The set-up time for any operation is included in the processing time;

$\checkmark$ The transportation time required for the movement of jobs between equipment is assumed to be negligible;

$\checkmark$ The operation cannot be interrupted;

$\checkmark \quad$ There are no precedence constraints among operations of different jobs.

\section{Parameters:}

\section{Model Formulation}

\section{$\mathrm{N}$ : Number of jobs}

M: Number of equipment

Phj: Processing time for job j on $\mathrm{m} / \mathrm{c} h, \mathrm{~h}=1,2, \ldots, \mathrm{M}, \mathrm{j}=1,2, \ldots, \mathrm{N}$

Dj: Due date of job j, j=1, 2, .., $N$

SEQ: Processing sequence array

NUMT: No. of equipment (tasks) for each job

NUMJ: No. of jobs per equipment $\mathrm{J}$

DISJ: Disjunction array. 


\section{Decision Variables:}

Cj: Completion time of job j

Shj: Starting time of job j on equipment $h$

Ej: Earliness of job $\mathrm{j}=(\mathrm{Dj}-\mathrm{Cj})$ if $\mathrm{Dj}>\mathrm{Cj}$ and 0 otherwise

Tj: Tardiness of job $\mathrm{j}=(\mathrm{Cj}-\mathrm{Dj})$ if $\mathrm{Cj}>\mathrm{Dj}$ and 0 otherwise

\subsection{Objective functions}

The three objectives that have been considered in this proposed model are; minimizing maximum completion time, minimizing total tardiness, and minimizing total earliness have been formulated in Equations 1,2 , and 3 respectively. While, the multi-objective function have been represented in Equation 4 where w1, w2 and $\mathrm{w} 3$ are the weights of three objectives respectively.

$$
\begin{aligned}
& \text { minimize } \mathrm{f} 1=\operatorname{MAX}(\mathrm{Cj}), \quad \forall \mathrm{j} \in \mathrm{N} \\
& \text { minimize } \mathrm{f} 2=\sum_{\mathrm{j} \in \mathrm{N}} \mathrm{Tj} \\
& \text { minimize } \mathrm{f} 3=\sum_{\mathrm{j} \in \mathrm{N}} \mathrm{Ej} \\
& \mathrm{MOF}=\mathrm{w} 1 \mathrm{f} 1+\mathrm{w} 2 \mathrm{f} 2+\mathrm{w} 3 \mathrm{f} 3
\end{aligned}
$$

\subsection{Constraints}

$$
\begin{aligned}
& \left(S_{h i}-S_{h j}\right) \geq P_{h j}-M Y_{h i j}, \forall i, j \in N, \forall h \in M \\
& \left(S_{h i}-S_{h j}\right) \geq P_{h j}-M\left(1-Y_{h i j}\right), \forall i, j \in N, \forall h \in M \\
& \sum_{h \in M}\left(S_{S E Q(j, l), j}+P_{S E Q(j, l), j}\right) \geq \sum_{h \in M} S_{S E Q(j, l+1), j}, \forall j \in N, \forall l \in M-1
\end{aligned}
$$

Constraints (5) and (6) are two mutually exclusive constraints. One of the constraints must be relaxed when job i precedes job j or j precedes i on equipment k to avoid overlapping between tasks (disjunction constraints).

Constraint (7) ensures the satisfaction of operational precedence between the tasks.

\section{Computational Results and Analysis}

In this section, the results of applying the proposed model are introduced. The model has been solved using Evolver solver and runs on an Intel ${ }^{\circledR}$ Core $^{\mathrm{TM}}$ i3-2310M CPU @2.10 GHz (3 GB of RAM). The GA parameters include; population size $\mathrm{N}=50$, number of generations $\mathrm{G}=40,000$, probability of crossover Pc $=0.5$, and probability of mutation $\mathrm{Pm}=0.1$.

The model accuracy and capability are verified through solving and analyzing four different projects. Three projects are of size $3 \mathrm{~J} * 3 \mathrm{M}$ and the fourth one is of size $5 \mathrm{~J} * 4 \mathrm{M}$. Each project is solved seven times to optimize seven different combinations of objectives as follows:

1) Maximum completion time

2) Total earliness

3) Total tardiness

4) The three objectives with equal weights

5) The three objectives giving double weight to the maximum completion time

6) The three objectives giving double weight to the total earliness

7) The three objectives giving double weight to the total tardiness

The results will be analyzed to compare the different objectives combination effect on the performance. 


\subsection{J x 3M Projects}

The model inputs; processing sequences, duration, and due dates of the three $3 \mathrm{~J} * 3 \mathrm{M}$ projects are shown in Tables 1,2 and 3.

Table 1: Job’s processing sequences

\begin{tabular}{|c|ccc|ccc|ccc|}
\cline { 2 - 11 } \multicolumn{1}{c|}{} & \multicolumn{3}{c|}{ Project 1 } & \multicolumn{3}{c|}{ Project 2 } & \multicolumn{3}{c|}{ Project 3 } \\
\hline J1 & 1 & 3 & --- & 1 & 3 & --- & 2 & 1 & 3 \\
\hline J2 & 2 & 1 & 3 & 2 & 1 & 3 & 1 & 3 & --- \\
\hline J3 & 3 & 1 & 2 & 3 & 1 & 2 & 3 & 1 & 2 \\
\hline
\end{tabular}

Table 2: Duration matrices of the processes

\begin{tabular}{|c|c|c|c|c|c|c|c|c|c|}
\cline { 2 - 11 } \multicolumn{1}{c|}{} & \multicolumn{3}{c|}{ Project 1 } & \multicolumn{3}{c|}{ Project 2 } & \multicolumn{3}{c|}{ Project 3 } \\
\cline { 2 - 11 } & J1 & J2 & J3 & J1 & J2 & J3 & J1 & J2 & J3 \\
\hline M1 & 30 & 22 & 14 & 14 & 22 & 11 & 32 & 32 & 12 \\
\hline M2 & ---- & 6 & 24 & --- & 23 & 21 & 12 & --- & 12 \\
\hline M3 & 6 & 11 & 21 & 12 & 13 & 22 & 12 & 32 & 12 \\
\hline
\end{tabular}

Table 3: Due dates of all jobs

\begin{tabular}{|c|c|c|c|c|c|c|c|c|c|}
\hline & \multicolumn{3}{|c|}{ Project 1} & \multicolumn{3}{|c|}{ Project 2} & \multicolumn{3}{|c|}{ Project 3} \\
\hline & J1 & J2 & J3 & J1 & J2 & J3 & J1 & J2 & J3 \\
\hline Due Date & 40 & 65 & 100 & 34 & 70 & 54 & 80 & 68 & 90 \\
\hline
\end{tabular}

The outputs of the model have been presented for the first project only for clarification taking the maximum completion time as a single objective representing set 1 . Table 4 shows the optimal start time and the corresponding finish time. The maximum completion time, earliness, and tardiness values are shown in Table 5. The schedule presented as a Gantt chart is in Figure 2.

Table 4: Results of the first project

\begin{tabular}{|l|c|c|c|c|c|c|c|c|}
\hline Series & 1 & 2 & 3 & 4 & 5 & 6 & 7 & 8 \\
\hline Job id & 1 & 1 & 2 & 2 & 2 & 3 & 3 & 3 \\
\hline Equipment required & 1 & 3 & 2 & 1 & 3 & 3 & 1 & 2 \\
\hline Duration time & 30 & 6 & 6 & 22 & 11 & 21 & 14 & 24 \\
\hline Start & 0 & 30 & 0 & 44 & 66 & 0 & 30 & 44 \\
\hline Finish time & 30 & 36 & 6 & 66 & 77 & 21 & 44 & 68 \\
\hline
\end{tabular}

Table 5: Completion time, earliness and tardiness (set 1)

\begin{tabular}{|l|c|c|c|}
\hline JOB & $\mathbf{1}$ & $\mathbf{2}$ & $\mathbf{3}$ \\
\hline Due Date & $\mathbf{4 0}$ & $\mathbf{6 5}$ & $\mathbf{1 0 0}$ \\
\hline Completion time & 36 & $\underline{77}$ & 68 \\
\hline Earliness & 4 & 0 & 32 \\
\hline Tardiness & 0 & 12 & 0 \\
\hline
\end{tabular}




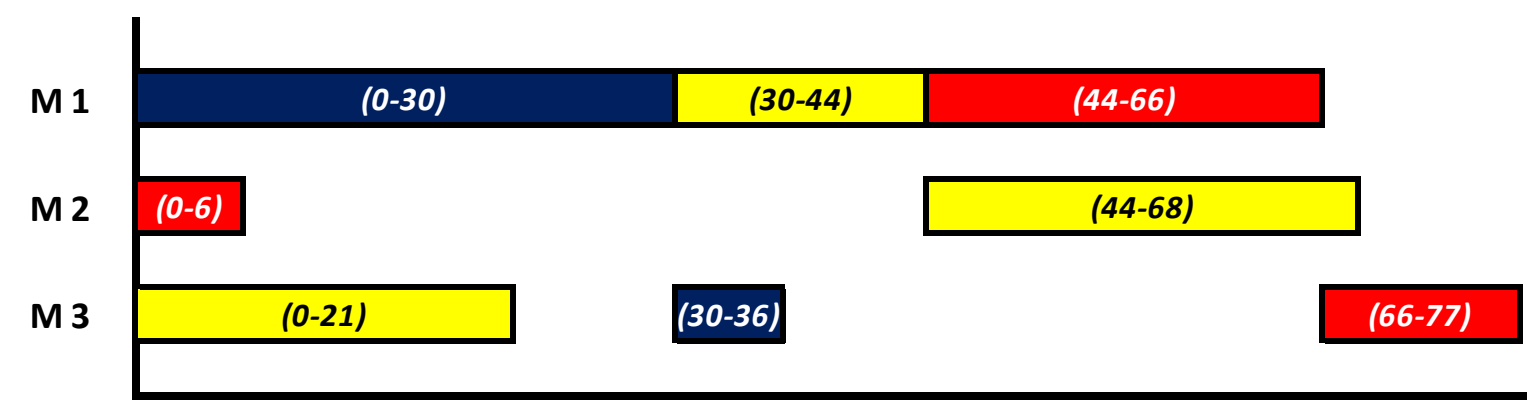

\section{\begin{tabular}{l|l|l|} 
J1 & J2 & J3 \\
\hline
\end{tabular}}

Figure 2. Gantt chart of the first project schedule

The same project has been solved using Lekin package and the best-achieved value using the heuristic of General SB Routine of the maximum completion time was the same value resulted using our proposed model of 77 time units. The Gantt chart of the Lekin schedule is shown in Figure 3.

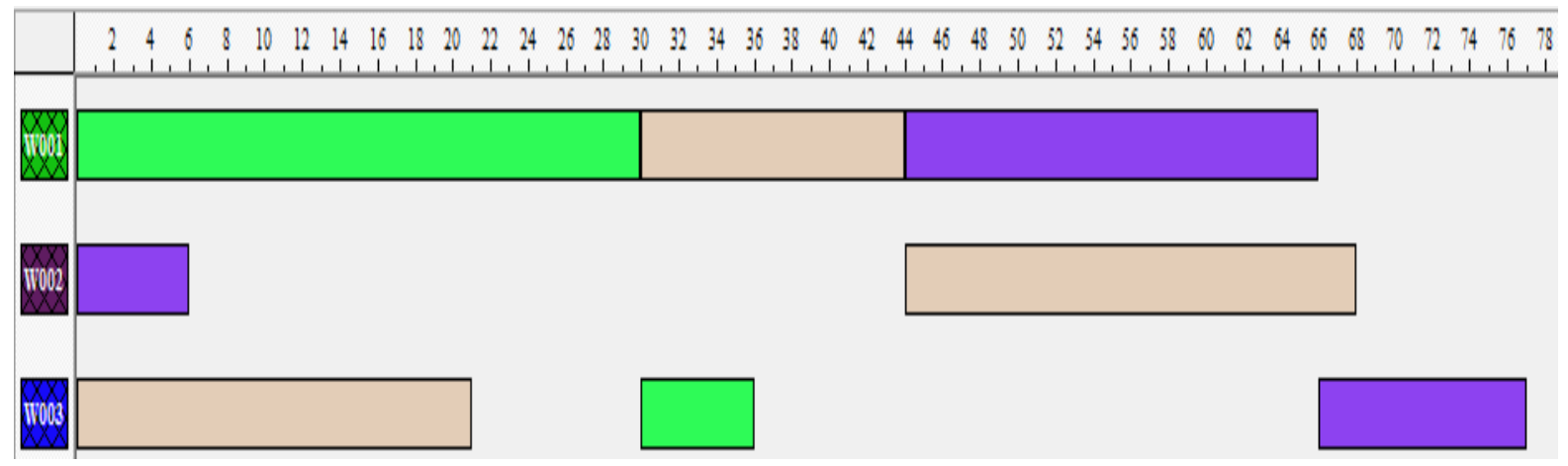

Figure 3. Gantt chart of the first project from Lekin

Both other two projects are solved using the proposed model and Lekin package and the best-achieved values using the heuristic of General SB Routine of the maximum completion time was the same value resulted using our proposed model of 68 and 88minutes. Gantt chart of the Lekin schedule is shown in Figure 4 and Figure 5.

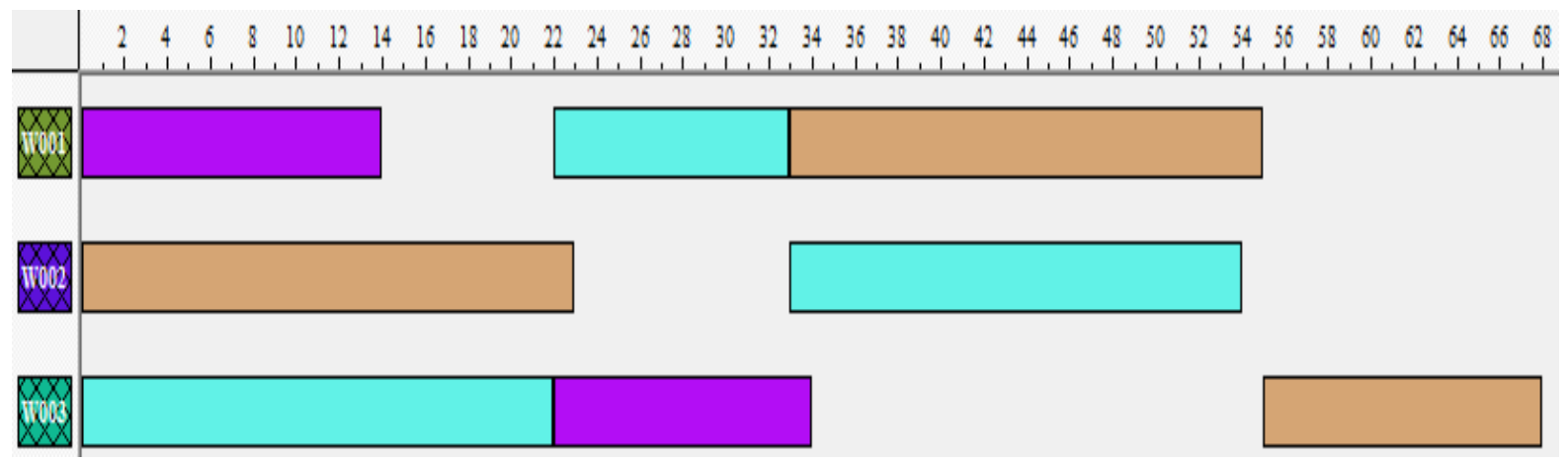

Figure 4. Gantt chart of the second project from Lekin

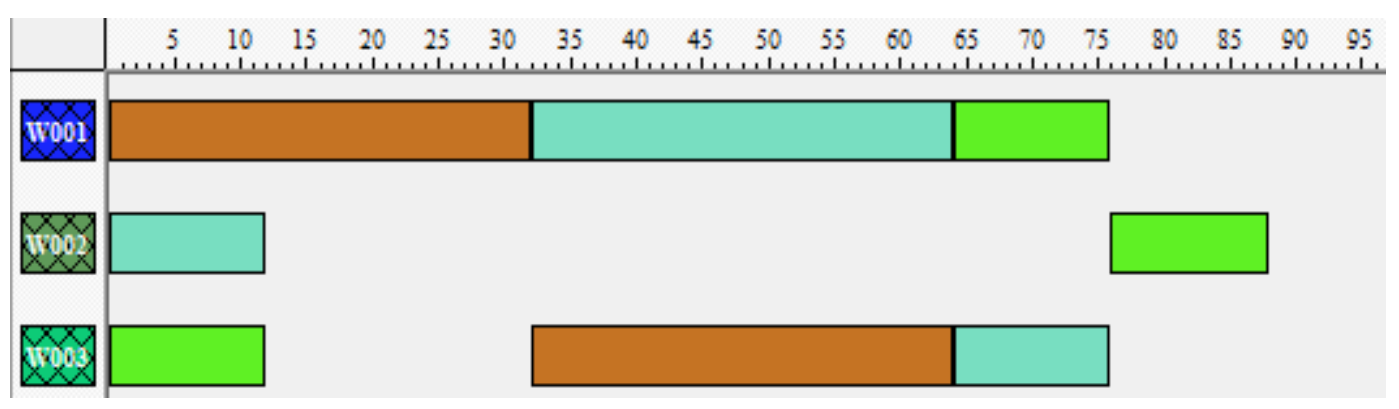

Figure 5. Gantt chart of the third project from Lekin 
Table 6: All objective's values of the 7 combinations of the three projects

\begin{tabular}{|c|c|c|c|c|c|c|c|c|}
\hline & Objective $\quad$ Combination & 1 & 2 & 3 & 4 & 5 & 6 & 7 \\
\hline \multirow{7}{*}{ تِّة } & Make Span & 77 & 205 & 90 & 98 & 77 & 100 & 92 \\
\hline & Total Earliness & 36 & 0 & 16 & 2 & 23 & 0 & 8 \\
\hline & Total Tardiness & 12 & 360 & 0 & 0 & 12 & 0 & 0 \\
\hline & Multi Objective & 125 & 565 & 106 & 100 & 112 & 100 & 100 \\
\hline & MO weighted Make Span & 202 & 770 & 196 & 198 & 189 & 200 & 192 \\
\hline & MO weighted T. Earliness & 161 & 565 & 122 & 102 & 135 & 100 & 108 \\
\hline & MO weighted T. Tardiness & 137 & 925 & 106 & 100 & 124 & 100 & 100 \\
\hline \multirow{7}{*}{ 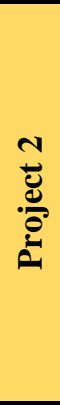 } & Make Span & 68 & 204 & 68 & 68 & 68 & 68 & 68 \\
\hline & Total Earliness & 2 & 0 & 2 & 2 & 2 & 2 & 2 \\
\hline & Total Tardiness & 0 & 406 & 0 & 0 & 0 & 0 & 0 \\
\hline & Multi Objective & 70 & 610 & 70 & 70 & 70 & 70 & 70 \\
\hline & MO weighted Make Span & 138 & 814 & 138 & 138 & 138 & 138 & 138 \\
\hline & MO weighted T. Earliness & 72 & 610 & 72 & 72 & 72 & 72 & 72 \\
\hline & MO weighted T. Tardiness & 70 & 1016 & 70 & 70 & 70 & 70 & 70 \\
\hline \multirow{7}{*}{ } & Make Span & 88 & 214 & 89 & 88 & 88 & 90 & 90 \\
\hline & Total Earliness & 38 & 0 & 9 & 2 & 2 & 0 & 0 \\
\hline & Total Tardiness & 8 & 348 & 0 & 0 & 0 & 8 & 0 \\
\hline & Multi Objective & 134 & 562 & 98 & 90 & 90 & 98 & 90 \\
\hline & MO weighted Make Span & 222 & 776 & 187 & 178 & 178 & 188 & 180 \\
\hline & MO weighted T. Earliness & 172 & 562 & 107 & 92 & 92 & 98 & 90 \\
\hline & MO weighted T. Tardiness & 142 & 910 & 98 & 90 & 90 & 106 & 90 \\
\hline
\end{tabular}

Table 6 shows the results' summary of all objective values of the 7 combinations in which it can be noticed that in the first combination where the only objective is to minimize the maximum completion time and the resulted optimal values are the best in all combinations. In combination 2 since the objective is to minimize the total earliness; the obtained total earliness is zero but the maximum completion time and total tardiness values are not optimal nor acceptable. While in combination 3 where the objective is to minimize the total tardiness; the resulted values of both maximum completion time and total earliness are reasonable but not the optimals.

The best and more reasonable and practical results are achieved in the sixth combination where there is no earliness no tardiness and the maximum completion time is conforming the due dates with small deviation from its best value where the three objectives are taken into consideration giving double weight to the total earliness.

\subsection{J*4M Project}

The model inputs; processing sequences, duration, and due dates of the $5 \mathrm{~J} * 4 \mathrm{M}$ projects are shown in Tables 7 and 8. While Table 9 presents the summary of results of all objectives' values of the 7 combinations.

Table 7: Job’s processing sequence

\begin{tabular}{|l|l|l|l|l|}
\hline J1 & 1 & 2 & 3 & 4 \\
\hline J2 & 1 & 2 & 3 & 4 \\
\hline J3 & 4 & 3 & 2 & \\
\hline J4 & 2 & 3 & 4 & 1 \\
\hline J5 & 1 & 3 & & \\
\hline
\end{tabular}


Table 8: Durations and due date

\begin{tabular}{|c|c|c|c|c|c|}
\hline $\mathbf{M} / \mathbf{J}$ & J1 & J2 & J3 & J4 & J5 \\
\hline $\mathbf{M 1}$ & 19 & 10 & & 14 & 15 \\
\hline M2 & & 30 & 15 & 10 & \\
\hline M3 & 10 & 18 & 18 & 20 & 16 \\
\hline M4 & 19 & 11 & 31 & 19 & \\
\hline Due Date & 100 & 115 & 90 & 85 & 31 \\
\hline
\end{tabular}

Table 9: Objectives values of project 4

\begin{tabular}{|l|c|c|c|c|c|c|c|}
\hline \multicolumn{1}{|c|}{ Combination } & $\mathbf{1}$ & $\mathbf{2}$ & $\mathbf{3}$ & $\mathbf{4}$ & $\mathbf{5}$ & $\mathbf{6}$ & $\mathbf{7}$ \\
\hline Make Span & & & & & & & \\
\hline Total Earliness & 92 & 220 & 109 & 111 & 109 & 115 & 111 \\
\hline Total Tardiness & 97 & 0 & 15 & 4 & 8 & 0 & 4 \\
\hline Multi Objective & 61 & 602 & 0 & 0 & 0 & 0 & 0 \\
\hline MO weighted Make Span & 250 & 822 & 124 & 115 & 117 & 115 & 115 \\
\hline MO weighted T. Earliness & 347 & 1042 & 233 & 226 & 226 & 230 & 226 \\
\hline MO weighted T. Tardiness & 311 & 1424 & 124 & 115 & 117 & 115 & 115 \\
\hline
\end{tabular}

The same project has been solved using Lekin package and the best-achieved value using the heuristic of General SB routine of the maximum completion time was the same value resulted using our proposed model of 92 time units. The Gantt chart of the Lekin schedule is shown in Figure 6.

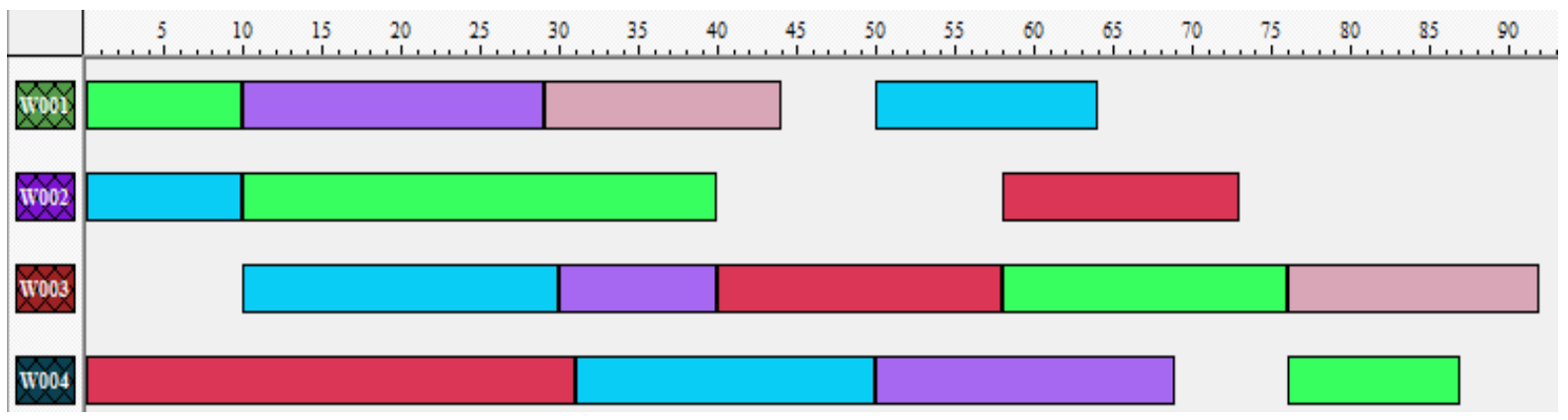

Figure 6. Gantt chart of the $5 \mathrm{~J}^{*} 4 \mathrm{M}$ project using Lekin.

From Table 9, it can be noticed that in the $5 \mathrm{~J} * 4 \mathrm{M}$ project in which it can be noticed that the best and more reasonable and practical results also are achieved in the sixth combination where there is no earliness no tardiness and the maximum completion time is conforming the due dates with small deviation from its best value where the three objectives are taken into consideration giving double weight to the total earliness.

\section{Conclusion}

This research has proposed a multi-objective scheduling model using Genetic Algorithms to minimize maximum completion time, total tardiness and total earliness criteria. The GA solver "Evolver" which is add-in Microsoft Excel spreadsheets is used in solving the proposed model. Multi-objective model is built in the spreadsheet environment using the built-in functions.

A set of problems has been used to examine the model and its effectiveness has been proven. The model has been proven through the analysis of results to be successful in reaching the optimal or near-optimal comparing to what is obtained for others like LEKIN.

Many other objectives like maximum tardiness, maximum earliness, and a minimum number of tardy jobs can be optimized easily using the proposed model. The proposed model is more flexible than other existing software with superior performance and accurate results comparing with what is obtained for others like LEKIN. 
Discussion and analysis of results have proven that the performance of a schedule often involves more than one aspect and, therefore requires a multi-objective treatment while single objective treatment has been not suitable in recent real life.

\section{Acknowledgment}

The authors thank Perfect Building Contracting Establishment for its support to do this research.

\section{References}

[1] M. R. Garey, D. S. Johnson, and R. Sethi, "The complexity of flow shop and job shop scheduling," Mathematics of operations research, vol. 1, pp. 117-129, 1976.

[2] M. Dell' Amico and M. Trubian, "Applying tabu search to the job-shop scheduling problem," Annals of Operations research, vol. 41, pp. 231-252, 1993.

[3] A. Ponsich and C. A. C. Coello, "A hybrid differential evolution — tabu search algorithm for the solution of job-shop scheduling problems," Applied Soft Computing, vol. 13, pp. 462-474, 2013.

[4] H. R. Lourenco, "Job-shop scheduling: Computational study of local search and large-step optimization methods," European Journal of Operational Research, vol. 83, pp. 347-364, 1995.

[5] M. Faccio, J. Ries, and N. Saggiorno, "Simulated annealing approach to solve dual resource constrained job shop scheduling problems: layout impact analysis on solution quality," International Journal of Mathematics in Operational Research, vol. 7, pp. 609-629, 2015.

[6] R. Cheng, M. Gen, and Y. Tsujimura, "A tutorial survey of job-shop scheduling problems using genetic algorithms-I. Representation," Computers \& industrial engineering, vol. 30, pp. 983-997, 1996.

[7] Y. Wang, "A new hybrid genetic algorithm for job shop scheduling problem," Computers \& Operations Research, vol. 39, pp. 22912299, 2012.

[8] D. Sha and C.-Y. Hsu, "A hybrid particle swarm optimization for job shop scheduling problem," Computers \& Industrial Engineering, vol. 51, pp. 791-808, 2006.

[9] T.-L. Lin, S.-J. Horng, T.-W. Kao, Y.-H. Chen, R.-S. Run, R.-J. Chen, et al., "An efficient job-shop scheduling algorithm based on particle swarm optimization," Expert Systems with Applications, vol. 37, pp. 2629-2636, 2010.

[10] K.-L. Huang and C.-J. Liao, "Ant colony optimization combined with taboo search for the job shop scheduling problem," Computers \& operations research, vol. 35, pp. 1030-1046, 2008.

[11] A. Udomsakdigool and V. Kachitvichyanukul, "Multiple colony ant algorithm for job-shop scheduling problem," International Journal of Production Research, vol. 46, pp. 4155-4175, 2008.

[12] P. Quanke, W. Ling, and G. Liang, "Differential evolution algorithm based on blocks on critical path for job shop scheduling problems," Journal of Mechanical Engineering, vol. 46, pp. 182-188, 2010.

[13] L. Gao, G. Zhang, L. Zhang, and X. Li, "An efficient memetic algorithm for solving the job shop scheduling problem," Computers \& Industrial Engineering, vol. 60, pp. 699-705, 2011.

[14] M. S. Al-Ashhab, Munshi, S., Oreijah, M., \& Ghulman, H., "Job Shop Scheduling Using Mixed Integer Programming," International Journal Of Modern Engineering Research, vol. 7, p. 7, 2017.

[15] K. R. Baker and B. Keller, "Solving the single-machine sequencing problem using integer programming," Computers \& Industrial Engineering, vol. 59, pp. 730-735, 2010.

[16] M. Al-Ashhab, "Multi-Objective Job Shop Scheduling Using a Lexicographic Procedure."

[17] H. M. Wagner, "An integer linear-programming model for machine scheduling," Naval Research Logistics (NRL), vol. 6, pp. 131-140, 1959.

[18] A. S. Manne, "On the job-shop scheduling problem," Operations Research, vol. 8, pp. 219-223, 1960.

[19] A. Scaria, K. George, and J. Sebastian, "An Artificial Bee Colony Approach for Multi-objective Job Shop Scheduling," Procedia Technology, vol. 25, pp. 1030-1037, 2016.

[20] K. P. Yoon and C.-L. Hwang, Multiple attribute decision making: an introduction vol. 104: Sage publications, 1995.

[21] F. $\quad$ I. $\quad$ Corporation. (2017). Goal Programming.

Available: http://www.maths.ed.ac.uk/hall/Xpress/FICO_Docs/optimizer/HTML/section5004.html

[22] E. Zitzler, K. Deb, and L. Thiele, "Comparison of multi objective evolutionary algorithms: Empirical results," Evolutionary computation, vol. 8, pp. 173-195, 2000.

[23] K. Deb, A. Pratap, S. Agarwal, and T. Meyarivan, "A fast and elitist multi objective genetic algorithm: NSGA-II," IEEE transactions on evolutionary computation, vol. 6, pp. 182-197, 2002.

[24] D. E. Goldberg, Genetic Algorithms in Search, Optimization and Machine Learning. MA: Addison-Wesley, Reading, 1989.

[25] D. Goldberg, "Genetic algorithms in search, optimization and Machine Learning Addison-Wesley Reading Google Scholar," 1989.

[26] D. Lei, "Simplified multi-objective genetic algorithms for stochastic job shop scheduling," Applied Soft Computing, vol. 11, pp. 49914996, 2011.

[27] J. Huang and G. A. Süer, "A dispatching rule-based genetic algorithm for multi-objective job shop scheduling using fuzzy satisfaction levels," Computers \& Industrial Engineering, vol. 86, pp. 29-42, 2015.

[28] M. Dorigo and L. M. Gambardella, "Ant colony system: a cooperative learning approach to the traveling salesman problem," IEEE Transactions on evolutionary computation, vol. 1, pp. 53-66, 1997.

[29] L. Ke, Q. Zhang, and R. Battiti, "MOEA/D-ACO: A multi objective evolutionary algorithm using decomposition and ant colony," IEEE transactions on cybernetics, vol. 43, pp. 1845-1859, 2013.

[30] R. Kuo and W. Cheng, "Hybrid meta-heuristic algorithm for job shop scheduling with due date time window and release time," The International Journal of Advanced Manufacturing Technology, vol. 67, pp. 59-71, 2013.

[31] Z.-h. Jia, C. Wang, and J. Y.-T. Leung, "An ACO algorithm for makespan minimization in parallel batch machines with non-identical job sizes and incompatible job families," Applied Soft Computing, vol. 38, pp. 395-404, 2016.

[32] R. Eberhart and J. Kennedy, "A new optimizer using particle swarm theory," in Micro Machine and Human Science, 1995. MHS'95., Proceedings of the Sixth International Symposium on, 1995, pp. 39-43.

[33] H. Hirano and T. Yoshikawa, "A study on two-step search based on PSO to improve convergence and diversity for Many-Objective Optimization Problems," in Evolutionary Computation (CEC), 2013 IEEE Congress on, 2013, pp. 1854-1859.

[34] F. Zhao, J. Tang, and J. Wang, "An improved particle swarm optimization with decline disturbance index (DDPSO) for multi-objective job-shop scheduling problem," Computers \& Operations Research, vol. 45, pp. 38-50, 2014. 
[35] L.-L. Liu, R.-S. Hu, X.-P. Hu, G.-P. Zhao, and S. Wang, "A hybrid PSO-GA algorithm for job shop scheduling in machine tool production," International Journal of Production Research, vol. 53, pp. 5755-5781, 2015.

[36] K. Shahnaghi, H. Shahmoradi-Moghadam, A. Noroozi, and H. Mokhtari, "A robust modelling and optimisation framework for a batch processing flow shop production system in the presence of uncertainties," International Journal of Computer Integrated Manufacturing, vol. 29, pp. 92-106, 2016.

[37] M. Gong, T. Hou, B. Fu, and L. Jiao, "A non-dominated neighbor immune algorithm for community detection in networks," in Proceedings of the 13th annual conference on Genetic and evolutionary computation, 2011, pp. 1627-1634.

[38] M. Costa and E. Minisci, "MOPED: a multi-objective Parzen-based estimation of distribution algorithm for continuous problems," in International Conference on Evolutionary Multi-Criterion Optimization, 2003, pp. 282-294.

[39] Y. Gao, L. Peng, F. Li, M. Liu, and X. Hu, "Eda-based multi-objective optimization using preference order ranking and multivariate gaussian copula," in International Symposium on Neural Networks, 2013, pp. 341-350.

[40] L. Wang, S. Wang, and M. Liu, "A Pareto-based estimation of distribution algorithm for the multi-objective flexible job-shop scheduling problem," International Journal of Production Research, vol. 51, pp. 3574-3592, 2013.

[41] B. Liu, Y. Fan, and Y. Liu, "A fast estimation of distribution algorithm for dynamic fuzzy flexible job-shop scheduling problem," Computers \& Industrial Engineering, vol. 87, pp. 193-201, 2015.

[42] I. Chaudhry, "Job shop scheduling problem with alternative machines using genetic algorithms," Journal of Central South University, vol. 19, pp. 1322-1333, 2012.

[43] I. A. Chaudhry, A. M. Khan, and A. A. Khan, "A genetic algorithm for flexible job shop scheduling," in Proceedings of the world congress on engineering, 2013, pp. 1-6.

[44] I. A. Chaudhry, R. Ahmed, and A. M. Khan, "Genetic Algorithm to minimize flowtime in a no-wait flowshop scheduling problem," in IOP Conference Series: Materials Science and Engineering, 2014, p. 012007.

[45] M. Al-Ashhab and H. Fadag, "MULTI-PRODUCT MASTER PRODUCTION SCHEDULING OPTIMIZATION MODELLING USING MIXED INTEGER LINEAR PROGRAMMING AND GENETIC ALGORITHMS," International Journal of Research GRANTHAALAYAH, vol. 6, p. 15, 2018.

[46] N. Palisade, "Guide to Evolver-The genetic algorithm solver for Microsoft Excel," ed: Newfield, NY: Palisade Corporation, 1998.

[47] H. Chen, J. Ihlow, and C. Lehmann, "A genetic algorithm for flexible job-shop scheduling," in Robotics and Automation, 1999. Proceedings. 1999 IEEE International Conference on, 1999, pp. 1120-1125.
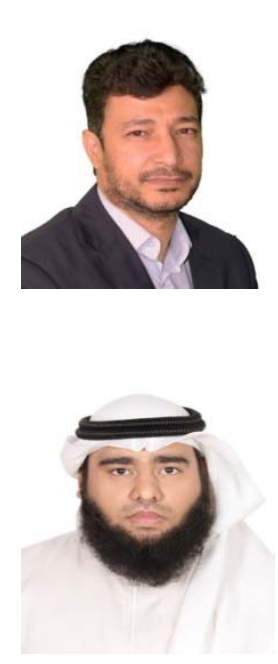

\section{AUTHOR PROFILE}

Mohammad Sayed Al-Ashhab born in Cairo, Egypt. He is an associate Professor in College of Engineering and Islamic Architecture, Umm Al Qura University, KSA. Received MSc and $\mathrm{PhD}$ degrees in Industrial Engineering from Ain Shams University, located in Cairo, Egypt. His research interests include supply chain networks design and planning, Optimization of production planning and scheduling, email: msashhab@uqu.edu.sa.

Ehab A. Mlybari received his MSc and PhD degrees in Civil Engineering, University of Leeds, UK. He is an Assistant Professor in College of Engineering and Islamic Architecture, Umm Al Qura University, KSA. His research centers on construction, management, value and risk analysis. He is an active member in several professional societies and institutes. He can use analytical, diagnostic, computational and management skills to solve challenging problems, develop innovative designs, and improve the performance of existing ones. email: eamlybari@uqu.edu.sa. 